ORIGINAL PAPER

\title{
RELATIONSHIP AMONG MISMATCH REPAIR DEFICIENCY, CDX2 LOSS, P53 AND E-CADHERIN IN COLON CARCINOMA AND SUITABILITY OF USING A DOUBLE PANEL OF MISMATCH REPAIR PROTEINS BY IMMUNOHISTOCHEMISTRY
}

\author{
Ilyas Sayar ${ }^{1}$, Emin Murat Akbas ${ }^{2}$, Arda Isik ${ }^{3}$, Aysun Gokce ${ }^{4}$, Kemal Peker ${ }^{3}$, Levent Demirtas ${ }^{2}$, \\ Mehmet GÜrbüZEL ${ }^{5}$ \\ ${ }^{1}$ Department of Pathology, Faculty of Medicine, Erzincan University, Erzincan, Turkey \\ ${ }^{2}$ Department of Internal Medicine, Faculty of Medicine, Erzincan University, Erzincan, Turkey \\ ${ }^{3}$ Department of General Surgery, Faculty of Medicine, Erzincan University, Erzincan, Turkey \\ ${ }^{4}$ Dışkapı Yıldırım Beyazıt Training Hospital, Ankara, Turkey \\ ${ }^{5}$ Department of Medical Biology, Faculty of Medicine, Erzincan University, Erzincan, Turkey
}

\begin{abstract}
Biomarkers such as mismatch repair proteins, CDX2, p53, and E-cadherin are blamed for colon cancers, but the relationships of these biomarkers with each other and with pathological risk factors in colon carcinoma are still not clear. The aim of this study was to evaluate the association of these biomarkers with each other by using immunohistochemical staining and to compare their expression with pathological risk factors for colonic adenocarcinoma. We also aimed to study the usability of a double panel of mismatch repair proteins. One hundred and eleven cases with colonic adenocarcinoma were examined. There was a statistically significant relationship between tumor histological differentiation and perineural invasion, vascular invasion, mismatch repair deficiency, p53, CDX2, and E-cadherin $(\mathrm{p}<0.05)$. PMS2 and MSH6 loss covered $100 \%$ of cases with mismatch repair deficiency. Mismatch repair deficiency was correlated with CDX2 loss and E-cadherin expression $(\mathrm{p}<0.05)$. It was also observed that cases with PMS2 loss covered all the cases with CDX2 loss. In conclusion, this double panel may be used instead of a quadruple panel for detecting mismatch repair deficiency. Association of CDX2 and PMS2 in the present study is necessary to conduct further genetic and pathological studies focusing on these two markers together.
\end{abstract}

Key words: Cdx2 protein, mismatch repair deficiency, E-cadherin, p53, colon cancer.

\section{Introduction}

Colon carcinomas (CCs) are commonly observed worldwide, and represent the most common cancer of the gastrointestinal system. Environmental and genetic factors play important roles in their etiology $[1$, 2]. Genetic susceptibility in CCs has been observed ranging from well-defined hereditary syndromes such as familial adenomatosis polyposis to syndromes in which heredity cannot be demonstrated [1, 2]. Understanding the molecular mechanisms in colon tumorigenesis has led to the development of new treatment strategies and new molecular tests. In molecular classification, various factors have been described, such as chromosomal instability, point mutations, and microsatellite instability (MSI) $[3,4,5,6]$. In recent years, some promising biomarkers have been found in molecular-level studies of CCs, and they have been 
used in clinical studies [7]. A defect in at least one of the set of DNA mismatch repair (MMR) genes (MLH1, MSH2, MSH6, and PMS2) that abrogate protein function is described as MMR deficiency. MSI testing with polymerase chain reaction and/or MMR protein immunohistochemistry are used to identify MMR deficiency in tumor tissue sections in which expression of MMR genes is lost while their expression in healthy adjacent tissue sections is intact [8].

In some centers, a double-antibody panel (MLH1 $+\mathrm{MSH} 2)$ is used for detecting MMR deficiency in CCs because of its sensitivity $[8,9,10]$. However, a four-antibody panel (MLH1, MSH2, MSH6, PMS2) has attracted increased interest in many centers for mismatch repair protein deficiency in both germline and sporadic CCs $[8,9,10]$. Although the diagnostic importance of MMR protein deficiency is known, lately there has not been clear use of single, double, or a greater number of markers in immunohistochemical (IHC) studies. In addition, there is an ongoing debate on the relationships between pathological risk factors and deficiencies in these proteins.

CDX2 is a nuclear homeobox transcription factor that is related to the CDX homeobox gene $[11$, 12]. In the last decade, CDX2 has been considered as a specific and sensitive biomarker in IHC studies, especially in colorectal adenocarcinomas [12, 13]. It was shown that $\mathrm{p} 53$ is an independent prognostic indicator of presence of metastasis and the later stages of CCs [14]. In addition, several studies have shown that inactivation of the P53 gene has a key role in the development of colorectal cancer [7, 15, 16]. It was reported that reduction in the expression of the E-cadherin molecule, one of the biomarkers used in our study, leads to the invasion of the cancer due to a decrease in intercellular adhesion in CCs and an increase in metastatic capacity $[17,18]$. However, the relationships of CDX2, p53, and E-cadherin with each other, with MMR deficiency and with classical pathological risk factors in CCs are still not clear.

Pathological analysis provides histological and molecular information in terms of appropriate treatment and prognosis. The aim of this study is to investigate the relationship among MMR proteins, CDX2, p53, E-cadherin and pathological risk factors in CCs using IHC staining. Moreover, we aimed to determine the practical and clinical usability of studying MMR proteins, regardless of sporadic or familial origins, in a single or double panel instead of a quadruple panel with IHC staining.

\section{Material and methods}

\section{Patient data}

One hundred and eleven patients who had been diagnosed with colon adenocarcinoma in the Erzincan University School of Medicine and Dışkapı Yıldırım Beyazit Training and Research Hospital between 2008 and 2014 were included in our study. Rectal cancers were excluded. Ethical consent was obtained from the local ethics commission for both groups. Because the nature of the study is retrospective, the status of cases - whether sporadic or inherited - was not known. The patients were reevaluated in terms of the parameters of histological differentiation (well/ moderate/poor), invasion depth (submucosa, muscularis propria, and serosa), lymphatic vessel invasion (positive/negative), lymph node metastasis (positive/ negative), perineural invasion (positive/negative), and vascular invasion (positive/negative). Slides of these cases obtained from the archive were reevaluated under light microscopy (Olympus BX53, Tokyo, Japan). We tried to select a paraffin-embedded tissue block for each case containing tumoral and preferably adjacent normal mucosa.

\section{Immunohistochemistry}

Four-micron sections were taken for positive charged slides by selecting appropriate formalin-fixed, paraffin-embedded tissue sections. Then, MLH1, MSH2, MSH6, PMS2, CDX-2, E-cadherin and p53 biomarkers (Table I) were studied using a fully automated IHC staining device (Leica Bond-Max, Melbourne, Australia).

Table I. Specifications of the biomarkers

\begin{tabular}{cccc}
\hline BIOMARKER & ClONE NO. & CompanY & Dilution RATE \\
\hline MLH1 & ES05 & Novocastra-Leica & $1: 100$ \\
\hline MSH2 & 25 D12 & Novocastra-Leica & $1: 50$ \\
\hline PMS2 & MOR4G & Novocastra-Leica & $1: 100$ \\
\hline MSH6 & PU29 & Novocastra-Leica & $1: 50$ \\
\hline CDX2 & AMT28 & Novocastra-Leica & $1: 100$ \\
\hline E- cadherin & SPM471 & Thermofisher & $1: 100$ \\
\hline P53 & DO-7+BP53-12 & Thermofisher & $1: 150$ \\
\hline
\end{tabular}




\section{Microscopic evaluation}

When evaluating immunostaining, nuclear staining of tumor cells was taken into account for MMR proteins and CDX2. For these markers, nuclear staining was assessed as absent: 0 and present: $1+$ (without evaluation of the percentage of staining). MMR deficiency was interpreted as a lack of at least one of the four proteins. In addition, tumor cells that showed no staining for nuclear staining for p53 and membranous staining for E-cadherin were considered 0 , those that indicated less than $5 \%$ staining were considered as $1+$, those that showed $5-50 \%$ staining were considered as $2+$, and those that indicated more than $50 \%$ staining were considered as $3+$. For all the biomarkers, staining of normal colonic glands or inflammatory cells was used as a positive control. Negative controls were tested with omission of the primary biomarkers.

\section{Statistical analysis}

Categorical variables were compared using the chi-square test. The degree of agreement of MMR

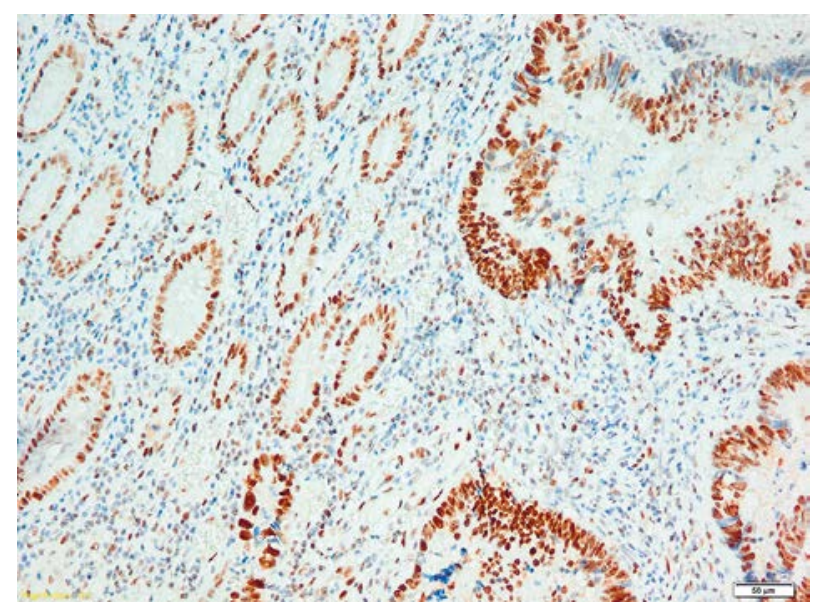

Fig. 1. Strong nuclear staining for MLH1 in colonic adenocarcinoma with positive control in normal colon glands and in inflammatory cells in the stroma (original magnification $200 \times$ )

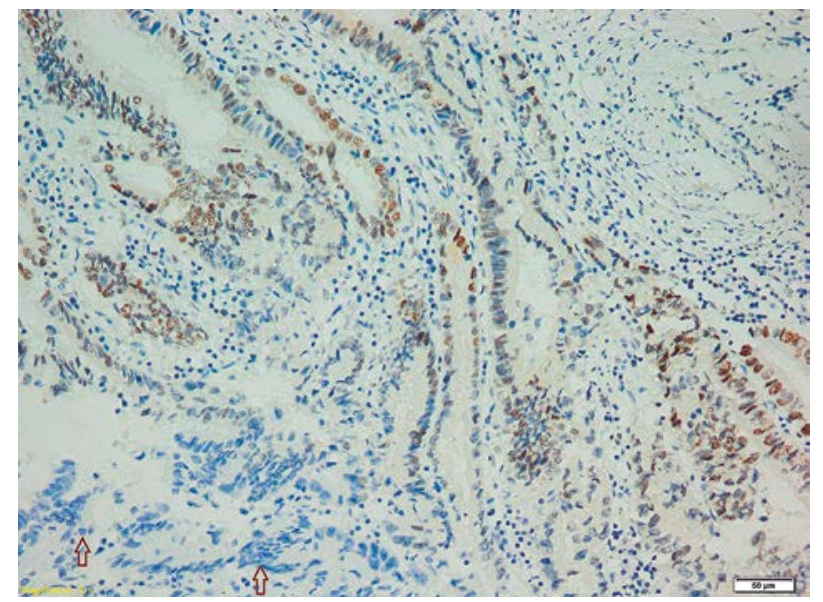

Fig. 3. MSH6 loss in tumor cells (red arrows) in colonic adenocarcinoma (original magnification $200 \times$ ) deficiency with MLH1, MSH2, MSH6, PMS2, PMS2 and/or MLH1, PMS2 and/or MSH2, and PMS2 and/ or MSH6, P53 and CDX2 tests was evaluated with the Cohen kappa ( $\kappa)$ test. A p-value $<0.05$ was considered as statistically significant. Analysis was conducted using R 3.1.0 (www.r-project.org).

\section{Results}

In the 111 patients with colon adenocarcinoma, the average age was 64.5 and $30.6 \%$ were female. There was lymph node metastasis in $62(55.9 \%)$ cases, lymphatic vessel invasion in $64(57.7 \%)$ cases, perineural invasion in $49(44.1 \%)$ cases and vascular invasion in $41(40.5 \%)$ cases. There was invasion limited to the submucosa in $6(5.4 \%)$ cases, muscularis propria invasion in $27(24.3 \%)$ cases, and serosa invasion in $80(70.3 \%)$ cases.

In IHC staining of all colon adenocarcinomas, there was MLH1 loss in $13(11.7 \%)$ patients, MSH2 loss in $9(8.1 \%)$, MSH6 loss in $10(9 \%)$, and PMS2 loss in $28(25.2 \%)$ (Fig. 1-4). There were only sev-

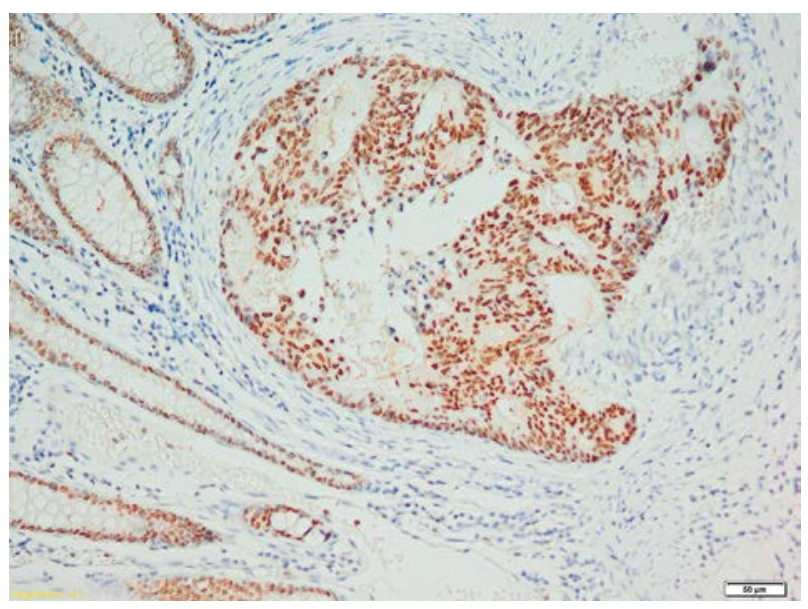

Fig. 2. Strong nuclear staining for $\mathrm{MSH} 2$ in colonic adenocarcinoma with positive control in normal colon glands (original magnification $200 \times$ )

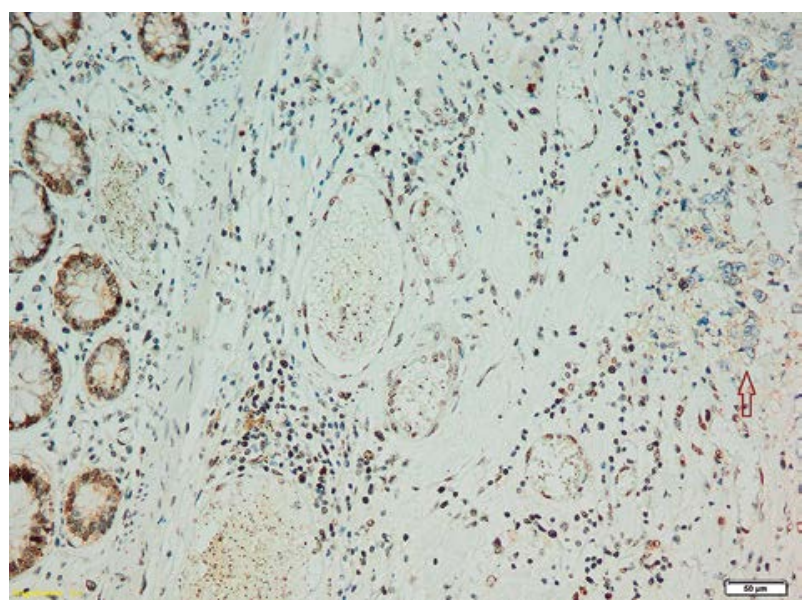

Fig. 4. PMS2 loss in tumor cells (red arrow) in colonic adenocarcinoma (original magnification $200 \times$ ) 
Table II. Comparison of MMR proteins among themselves and with P53- CDX2.

\begin{tabular}{|c|c|c|c|c|c|c|c|c|c|c|c|c|c|c|c|c|c|c|}
\hline \multirow{2}{*}{$\begin{array}{l}\text { MMR } \\
\text { PROTEIN } \\
\text { STATUS }\end{array}$} & \multicolumn{2}{|c|}{ MLH1 } & \multicolumn{2}{|c|}{ MSH2 } & \multicolumn{2}{|c|}{ MSH6 } & \multicolumn{2}{|c|}{ PMS2 } & \multicolumn{2}{|c|}{$\begin{array}{l}\text { PMS2- } \\
\text { MLH1 }\end{array}$} & \multicolumn{2}{|c|}{$\begin{array}{l}\text { PMS2- } \\
\text { MSH2 }\end{array}$} & \multicolumn{2}{|c|}{$\begin{array}{l}\text { PMS2- } \\
\text { MSH6 }\end{array}$} & \multicolumn{2}{|c|}{ P53 } & \multicolumn{2}{|c|}{$\mathrm{CDX} 2$} \\
\hline & 1 & 0 & 1 & 0 & 1 & 0 & 1 & 0 & 1 & 0 & 1 & 0 & 1 & 0 & $1 *$ & 0 & 1 & 0 \\
\hline 1 & 82 & 0 & 82 & 0 & 82 & 0 & 82 & 0 & 80 & 2 & 82 & 0 & 82 & 0 & 68 & 14 & 82 & 0 \\
\hline 0 & 16 & 13 & 20 & 9 & 19 & 10 & 1 & 28 & 3 & 26 & 1 & 28 & 0 & 29 & 24 & 5 & 18 & 11 \\
\hline$\kappa$ & \multicolumn{2}{|c|}{0.55} & \multicolumn{2}{|c|}{0.40} & \multicolumn{2}{|c|}{0.44} & \multicolumn{2}{|c|}{0.98} & \multicolumn{2}{|c|}{0.88} & \multicolumn{2}{|c|}{0.98} & & \multicolumn{2}{|c|}{0.02} & \multicolumn{2}{|c|}{0.47} \\
\hline $\mathrm{p}$ & \multicolumn{2}{|c|}{$<0.001$} & \multicolumn{2}{|c|}{$<0.001$} & \multicolumn{2}{|c|}{$<0.001$} & \multicolumn{2}{|c|}{$<0.001$} & \multicolumn{2}{|c|}{$<0.001$} & \multicolumn{2}{|c|}{$<0.001$} & \multicolumn{2}{|c|}{$<0.001$} & \multicolumn{2}{|c|}{0.984} & \multicolumn{2}{|c|}{$<0.001$} \\
\hline
\end{tabular}

The agreement with Cohen $\kappa$ values was as follows: 0-0.20, very poor; 0.21-0.40, poor; 0.41-0.60, fair; 0.61-0.80, good; and 0.81-1.00, excellent. Deficiency of variable $=0$ and presence of variable $=1$.* To apply Cohen $\kappa$ test, $+1,+2,+3$ staining with P53 were considered as +1 .

en cases with a concordant nonstaining pattern with four MMR proteins. Isolated MSH6 loss was seen in only one case, while isolated PMS2 loss was seen in 12 cases. There was no isolated MLH1 or MSH2 loss. The degree of agreement between MMR protein deficiency and the loss of MMR proteins (alone and paired) from strong to poor was as follows: PMS2MSH6, PMS2-MSH2, PMS2, PMS2-MLHI, MLH1, MSH6, and MSH2 (Table II).

With CDX2 there was no staining in $11(9.9 \%)$ cases (Fig. 5). Staining with p53 was not detected in $19(17.1 \%)$ cases, while 18 cases $(16.2 \%)$ had $1+$ staining, 40 cases $(36.0 \%)$ had $2+$ staining, and 34 cases $(30.6 \%)$ had $3+$ staining (Fig. 6). Staining with E-cadherin was detected in all carcinomas, with 29 cases $(26.1 \%)$ having $1+$ staining, 26 cases $(23.4 \%)$ having $2+$ staining, and 56 cases $(50.5 \%)$ having $3+$ staining (Fig. 7). Tumor histological differentiation was found to be statistically related to perineural invasion, vascular invasion, p53, CDX2, and E-cadherin $(\mathrm{p}<0.05)$ (Table III). In addition, there was a statistically significant relationship between the MMR proteins, such as only MLH1 loss, only PMS2 loss, loss of PMS2 paired with other MMR proteins, and MMR deficiency presence with histological differentiation $(\mathrm{p}<0.05)$. However, there was no significant relationship among sex,

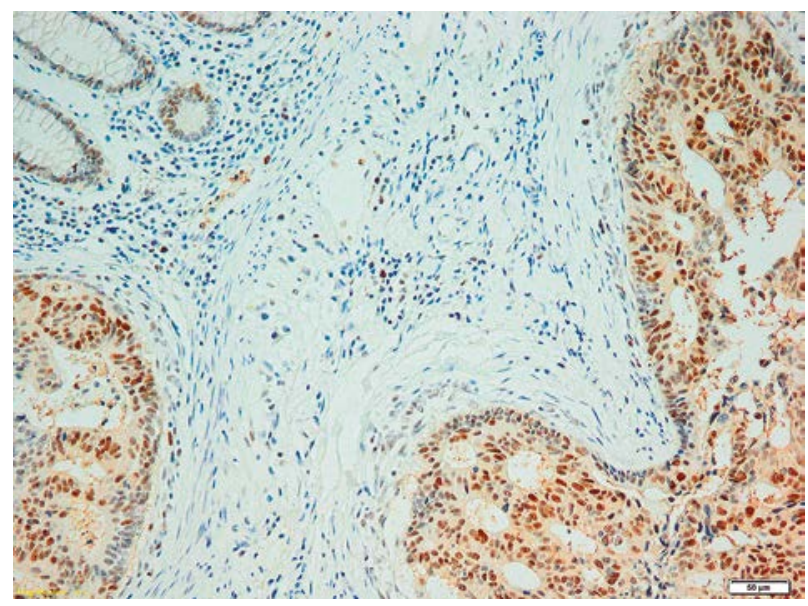

Fig. 6. Strong nuclear staining in tumor cells for $\mathrm{p} 53$ in colonic adenocarcinoma (original magnification $200 \times$ ) lymph node metastasis, lymphatic vessel invasion, tumor depth, only MSH2 loss, or only MSH6 loss with histological differentiation ( $\mathrm{p}>0.05)$.

Twenty-eight patients with PMS2 loss within the 29 patients with MMR deficiency covered all 11 patients (100\%) with CDX2 deficiency while covering only 5 of 19 cases $(26.3 \%)$ with P53 loss. Unfortunately, because of staining of all cases this association has not been evaluated with E-cadherin.

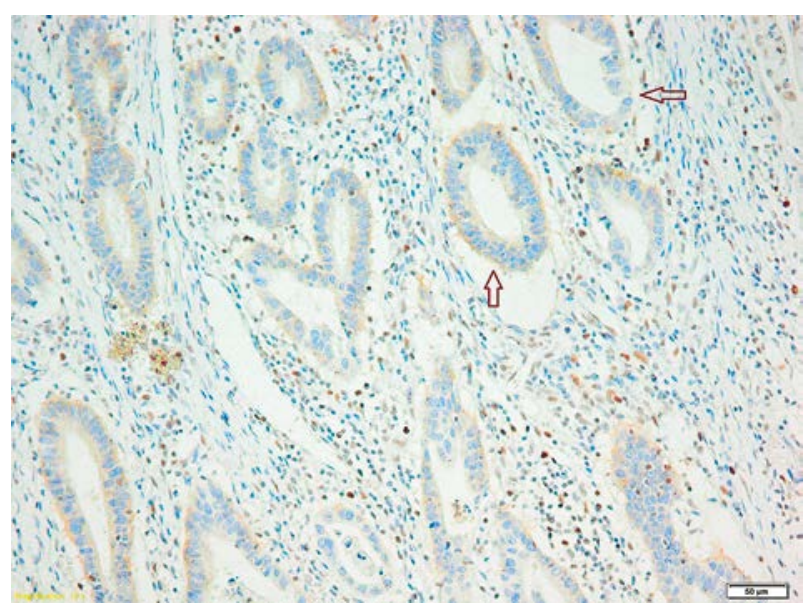

Fig. 5. CDX2 loss in tumoral gland cells (red arrows) in colonic adenocarcinoma (original magnification $200 \times$ )

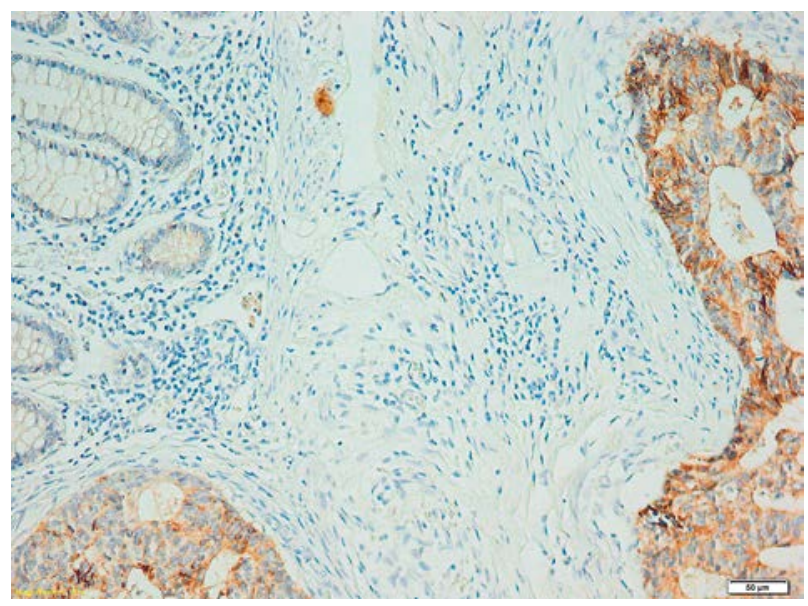

Fig. 7. Strong membranous staining for E-cadherin in colonic adenocarcinoma (original magnification $200 \times$ ) 
Table III. Association of histological differentiation and other parameters

\begin{tabular}{|c|c|c|c|c|c|}
\hline \multirow{2}{*}{$\begin{array}{l}\text { VARIABLES } \\
\text { CATEGORICAL VARIABLES }\end{array}$} & & \multicolumn{3}{|c|}{ DIFFERENTIATION } & \multirow[t]{2}{*}{ P VAlue } \\
\hline & & $\begin{array}{l}\text { WeLL } \\
\text { N }(\%)\end{array}$ & $\begin{array}{l}\text { MODERATE } \\
\mathrm{N}(\%)\end{array}$ & $\begin{array}{l}\text { PoOR } \\
\text { N }(\%)\end{array}$ & \\
\hline \multirow[t]{2}{*}{ Sex } & Male & $22(64.7)$ & $27(54.0)$ & $21(77.8)$ & \multirow[t]{2}{*}{0.116} \\
\hline & Female & $12(35.3)$ & $23(46.0)$ & $6(22.2)$ & \\
\hline \multirow[t]{2}{*}{ Lymph node metastasis } & No & $19(55.9)$ & $21(42.0)$ & $9(33.3)$ & \multirow[t]{2}{*}{0.195} \\
\hline & Yes & $15(44.1)$ & $29(58.0)$ & $18(66.7)$ & \\
\hline \multirow[t]{2}{*}{ Lymphatic vessel invasion } & No & $19(55.9)$ & $19(38.0)$ & $9(33.3)$ & \multirow[t]{2}{*}{0.147} \\
\hline & Yes & $15(44.1)$ & $31(62.0)$ & $18(66.7)$ & \\
\hline \multirow[t]{3}{*}{ Invasion depth } & Submucosa & $2(5.9)$ & $3(6.0)$ & $1(3.7)$ & \multirow[t]{3}{*}{0.146} \\
\hline & Muscle Layer & $13(38.2)$ & $11(22.0)$ & $3(11.1)$ & \\
\hline & Serosa & $19(55.9)$ & $36(72.0)$ & $23(85.2)$ & \\
\hline \multirow[t]{2}{*}{ Perineural invasion } & No & $25(73.5)$ & $24(48.0)$ & $13(48.1)$ & \multirow[t]{2}{*}{0.045} \\
\hline & Yes & $9(26.5)$ & $26(52.0)$ & $14(51.9)$ & \\
\hline \multirow[t]{2}{*}{ Vascular invasion } & No & $28(82.4)$ & $29(58.0)$ & $13(48.1)$ & \multirow[t]{2}{*}{0.014} \\
\hline & Yes & $6(17.6)$ & $21(42.0)$ & $14(51.9)$ & \\
\hline \multirow[t]{4}{*}{ P53 } & 0 & $11(32.4)$ & $3(6.0)$ & $5(18.5)$ & \multirow[t]{4}{*}{$<0.001$} \\
\hline & +1 & $12(35.3)$ & $5(10.0)$ & $1(3.7)$ & \\
\hline & +2 & $7(20.6)$ & $27(54.0)$ & $6(22.2)$ & \\
\hline & +3 & $4(11.8)$ & $15(30.0)$ & $15(55.6)$ & \\
\hline \multirow[t]{2}{*}{$\mathrm{CDX} 2$} & 0 & $1(2.9)$ & $3(6.0)$ & 7 (25.9) & \multirow[t]{2}{*}{0.005} \\
\hline & +1 & $33(97.1)$ & $47(94.0)$ & $20(74.1)$ & \\
\hline \multirow[t]{3}{*}{ E-cadherin } & +1 & $3(6)$ & $2(4.1)$ & 24 (88.9) & \multirow[t]{3}{*}{$<0.001$} \\
\hline & +2 & $7(20.5)$ & $19(38.8)$ & $0(0)$ & \\
\hline & +3 & $25(73.5)$ & $28(57.1)$ & $3(11.1)$ & \\
\hline \multirow[t]{2}{*}{ MLH-1 } & 0 & $1(2.9)$ & $3(6.0)$ & $9(33.3)$ & \multirow[t]{2}{*}{$<0.001$} \\
\hline & +1 & $33(97.1)$ & $47(94.0)$ & $18(66.7)$ & \\
\hline \multirow[t]{2}{*}{ MSH2 } & 0 & $2(5.9)$ & $2(4.0)$ & $5(18.5)$ & \multirow[t]{2}{*}{0.071} \\
\hline & +1 & $32(94.1)$ & $48(96.0)$ & $22(81.5)$ & \\
\hline \multirow[t]{2}{*}{ MSH6 } & 0 & $3(8.8)$ & $2(4.0)$ & $5(18.5)$ & \multirow[t]{2}{*}{0.105} \\
\hline & +1 & $31(91.2)$ & $48(96.0)$ & $22(81.5)$ & \\
\hline \multirow[t]{2}{*}{ PMS2 } & 0 & $4(11.8)$ & $3(6.0)$ & $21(77.8)$ & $<0.001$ \\
\hline & +1 & $30(88.2)$ & 47 (94.0) & $6(22.29)$ & \\
\hline MMR status & 0 & $29(85.3)$ & $47(94.0)$ & $6(22.2)$ & $<0.001$ \\
\hline & +1 & $5(14.7)$ & $3(6.0)$ & $21(77.8)$ & \\
\hline PMS2 and/or MSH6 & 0 & $5(14.7)$ & $3(6.0)$ & $21(77.8)$ & $<0.001$ \\
\hline & +1 & $29(85.3)$ & $47(94.0)$ & $6(22.22)$ & \\
\hline
\end{tabular}


On the other hand, there were statistically significant relationships and strong cohesion among MMR status, only MLH1 loss, only MSH2 loss, only MSH6 loss, only PMS2 loss, PMS2 and/or MSH6 loss, CDX2 loss, and E-cadherin expression when each of these was compared individually to the others $(\mathrm{p}<0.05)$. There was no significant relationship between these biomarkers and sex, lymph node metastasis, lymphatic vessel invasion, perineural invasion, vascular invasion, or $\mathrm{p} 53$ expression ( $\mathrm{p}>0.05$ ).

\section{Discussion}

There have been few studies specifying the use of dual protein panels in the literature, although the quadruple panel has been used to identify the lack of MMR proteins as one of the influential factors in colon carcinoma tumorigenesis $[8,9,10]$. However, studies on the correlation and coherence of MMR proteins with each other as a product of different perspectives via IHC staining are very limited. For instance, Shia $e t$ al. claimed that the dual panel (PMS2 and/or MSH6) can be used instead of the quadruple panel [8]. Moreover, Hall et al. found that the dual panel is $100 \%$ sensitive and specific when compared with the quadruple panel [9]. In the present study, we found that MMR deficiency had a moderately statistically significant relationship with only MSH2 loss, only MSH6 loss, and only MLH1 loss, while it had a high statistically significant relationship with only PMS2 loss and PMS2 and/ or MSH6 loss. The rates of PMS2 and/or MSH6 loss were compared with MMR deficiency (100\%), and the results were compatible with the findings of Hall et al. [9]. In addition, it was remarkable that the cases with PMS2 loss comprised 98\% of the cases with MMR deficiency. On the other hand, when MMR profiles were compared with each other, the results were statistically significant. According to these data, it has been concluded that single or double panels do not affect diagnosis, treatment or prognosis.

Hall et al. suggested that using a double panel instead of a quadruple one is more beneficial in terms of time and economy [9]. Similar to the mentioned study, our findings support studying a single (PMS2) or double panel (PMS2 and MSH6) with automated immunohistochemistry instead of a quadruple panel. On the other hand, they reported MMR deficiency of $30.2 \%$ and an isolated PMS2 loss rate of about $1 \%$ in CCs. In the present study, MMR deficiency was found to be $26.1 \%$ regardless of sporadic or familial origins. In addition, isolated PMS2 deficiency was detected in $41.4 \%$ of all MMR deficiency cases. The high isolated PMS2 deficiency found in our study compared to the study by Hall et al. may reveal the sensitivity and importance of this protein.

While CDX2 expression was found in $98-100 \%$ of CCs in some studies, it was observed in $63-86 \%$ in others $[13,19,20,21]$. In a similarly high rate to their data, in our study, while CDX2 expression in CCs was $90.1 \%$, which is comparable with the literature, the staining rate in normal colon mucosa was $99 \%$. On the other hand, it is quite interesting that the group of patients with PMS2 loss covered all patients with CDX2 deficiency. According to our extensive literature research, no study has detected this correlation before.

In the literature, some studies have been conducted using pairwise comparison of CDX2, MMR proteins, E-cadherin, and $\mathrm{p} 53$ biomarkers using IHC staining in CC patients $[19,20,21,22,23,24,25$, $26,27,28,29,30,31,32,33]$. According to our literature search, there have been no studies evaluating all of these markers together via IHC staining. Loss of CDX2 has been associated with high-grade tumors in colon tumors and advanced tumor stage $[13,22,23,24,25,26]$. It has also been noted that there is a relationship between poor differentiation and loss of E-cadherin expression [27, 28, 29]. Moreover, there is a reported relationship between poorly differentiated tumors and MMR protein loss [30, 31]. According to our data, MMR protein deficiency, loss of CDX2, and loss of E-cadherin were associated with decreased tumor histological differentiation, and it is considered that these biomarkers may be associated with differentiation. However, there was no statistical relationship between MMR, CDX2, or E-cadherin and the prognostic risk factors other than differentiation. Although the relationship between CDX2 loss and MMR protein deficiency has been reported in other studies, in accordance with our research [11, 13, 22, 23, 32], there have been other studies reporting no relationship between the two [25, 33, 34, 35]. In addition, Funakoshi et al. claimed in a study investigating the relationship between CDX2 and E-cadherin that the former plays a regulatory role in the expression of the latter [36]. In another study of colorectal cancer with MMR proficiency and MLH1 loss, increased expression of nuclear beta-catenin and membranous E-cadherin loss were reported as independent negative pathological risk factors [37]. In our study, there was also a relationship between E-cadherin expression and CDX2 and MMR protein loss using IHC staining.

In some research, $\mathrm{p} 53$ protein expression was reported to be associated with poor prognosis in CCs $[7,15,16]$. While a relationship of p53 expression with increased stage and reduced histological differentiation of tumor and increased depth of tumor invasion has been shown in some studies [38, 39], no relationship has been found in other studies $[40,41]$. In our research, p53 expression increased with decreased tumor differentiation and increased tumor invasion depth. Except for these parameters, there was no significant relationship of $\mathrm{p} 53$ with other prog- 
nostic pathological factors. It has been stated that mutation of $\mathrm{p} 53$ as a tumor suppressor gene is effective in the later stages of tumor development [14]. It has been also reported that CDX2 suppresses many genes that are effective in processes such as tumorigenesis, cell proliferation, and cell migration [42]. In addition, it has been proposed that CDX2 is a tumor suppressor molecule in the mouse model [42]. Baba et al. found a correlation between p 53 and CDX2 loss [25]. Moreover, Valentini et al. found a relationship between $\mathrm{p} 53$ hyperexpression and MMR protein deficiency [43]. However, in our study, there was no relationship between $\mathrm{p} 53$ expression and MMR proteins, E-cadherin, or CDX2 expression.

The results of the present study highlight the association and correlation of MMR deficiency with CDX2 loss and E-cadherin expression in patients with CC. Additionally, it is interesting that the patients with PMS2 loss covered all patients with CDX2 loss. These findings confirm that it is necessary to conduct further genetic and pathological studies focusing on these two markers together. On the other hand, we presume it is important evidence that only PMS2 or the combination of PMS2 with MSH6 may be sufficient in the detection of MMR protein deficiency with IHC staining. Studying the remaining MMR proteins may be more suitable in terms of time (average process time: 4 hours), cost, and labor when deficiency is not detected with PMS2 or especially in combination with MSH6.

\section{The authors declare no conflict of interest.}

\section{References}

1. Tárraga López PJ, Albero JS, Rodríguez-Montes JA. Primary and secondary prevention of colorectal cancer. Clin Med Insights Gastroenterol 2014; 7: 33-46.

2. Jasperson KW, Tuohy TM, Neklason DW, et al. Hereditary and familial colon cancer. Gastroenterology 2010; 138: 20442058.

3. Domingo E, Ramamoorthy R, Oukrif D, et al. Use of multivariate analysis to suggest a new molecular classification of colorectal cancer. J Pathol 2013; 229: 441-448.

4. Jass JR. Classification of colorectal cancer based on correlation of clinical, morphological and molecular features. Histopathology 2007; 50: 113-130.

5. Gavin PG, Colangelo LH, Fumagalli D, et al. Mutation profiling and microsatellite instability in stage II and III colon cancer: an assessment of their prognostic and oxaliplatin predictive value. Clin Cancer Res 2012; 18: 6531-6541.

6. Watanabe T, Wu TT, Catalano PJ, et al. Molecular predictors of survival after adjuvant chemotherapy for colon cancer. N Engl J Med 2001; 344: 1196-1206.

7. Tejpar S, Bertagnolli M, Bosman F, et al. Prognostic and predictive biomarkers in resected colon cancer: current status and future perspectives for integrating genomics into biomarker discovery. Oncologist 2010; 15: 390-404.

8. Shia J, Tang LH, Vakiani E, et al. Immunohistochemistry as first-line screening for detecting colorectal cancer patients at risk for hereditary nonpolyposis colorectal cancer syndrome: a 2-antibody panel may be as predictive as a 4 -antibody panel. Am J Surg Pathol 2009; 33: 1639-1645.

9. Hall G, Clarkson A, Shi A, et al. Immunohistochemistry for PMS2 and MSH6 alone can replace a four antibody panel for mismatch repair deficiency screening in colorectal adenocarcinoma. Pathology 2010; 42: 409-413.

10. Hicks SC, Ward RL and Hawkins NJ. Immunohistochemistry for PMS2 and MSH6 alone can replace a four antibody panel for mismatch repair deficiency screening in colorectal adenocarcinoma. Pathology 2011; 43: 84-85; author reply 85-86.

11. Saad RS, Ghorab Z, Khalifa MA, et al. CDX2 as a marker for intestinal differentiation: Its utility and limitations. World J Gastrointest Surg 2011; 3: 159-166.

12. Beck F. The role of $\mathrm{Cdx}$ genes in the mammalian gut. Gut 2004; 53: 1394-1396.

13. Kaimaktchiev V, Terracciano L, Tornillo L, et al. The homeobox intestinal differentiation factor CDX2 is selectively expressed in gastrointestinal adenocarcinomas. Mod Pathol 2004; 17: 1392-1399.

14. Palmer DG, Paraskeva C, Williams AC. Modulation of $\mathrm{p} 53$ expression in cultured colonic adenoma cell lines by the naturally occurring lumenal factors butyrate and deoxycholate. Int J Cancer 1997; 73: 702-706.

15. Popat S, Chen Z, Zhao D, et al. A prospective, blinded analysis of thymidylate synthase and p53 expression as prognostic markers in the adjuvant treatment of colorectal cancer. Ann Oncol 2006; 17: 1810-1817.

16. Einspahr JG, Martinez ME, Jiang R, et al. Associations of Kiras proto-oncogene mutation and $\mathrm{p} 53$ gene overexpression in sporadic colorectal adenomas with demographic and clinicopathologic characteristics. Cancer Epidemiol Biomarkers Prev 2006; 15: 1443-1450.

17. Tsanou E, Peschos D, Batistatou A, et al. The E-cadherin adhesion molecule and colorectal cancer. A global literature approach. Anticancer Res 2008; 28: 3815-3826.

18. Elzagheid A, Kuopio T, Ilmen M, et al. Prognostication of invasive ductal breast cancer by quantification of E-cadherin immunostaining: the methodology and clinical relevance. Histopathology 2002; 41: 127-133.

19. Lugli A, Tzankov A, Zlobec I, et al. Differential diagnostic and functional role of the multi-marker phenotype CDX2/CK20/ CK7 in colorectal cancer stratified by mismatch repair status. Mod Pathol 2008; 21: 1403-1412.

20. Moskaluk CA, Zhang H, Powell SM, et al. Cdx2 protein expression in normal and malignant human tissues: an immunohistochemical survey using tissue microarrays. Mod Pathol 2003; 16: 913-919.

21. Werling RW, Yaziji H, Bacchi CE, et al. CDX2, a highly sensitive and specific marker of adenocarcinomas of intestinal origin: an immunohistochemical survey of 476 primary and metastatic carcinomas. Am J Surg Pathol 2003; 27: 303-310.

22. Bakaris S, Cetinkaya A, Ezberci F, et al. Expression of homeodomain protein CDX2 in colorectal adenoma and adenocarcinoma. Histol Histopathol 2008; 23: 1043-1047.

23. Hinoi T, Tani M, Lucas PC, et al. Loss of CDX2 expression and microsatellite instability are prominent features of large cell minimally differentiated carcinomas of the colon. Am J Pathol 2001; 159: 2239-2248.

24. Choi BJ, Kim CJ, Cho YG, et al. Altered expression of CDX2 in colorectal cancers. APMIS 2006; 114: 50-54.

25. Baba Y, Nosho K, Shima K, et al. Relationship of CDX2 loss with molecular features and prognosis in colorectal cancer. Clin Cancer Res 2009; 15: 4665-4673.

26. Rosty C, Williamson EJ, Clendenning M, et al. Should the grading of colorectal adenocarcinoma include microsatellite instability status? Hum Pathol 2014; 45: 2077-2084.

27. Mogoanta SS, Vasile I, Totolici B, et al. Colorectal cancer clinical and morphological aspects. Rom J Morphol Embryol 2014; 55: 103-110. 
28. Elzagheid A, Algars A, Bendardaf R, et al. E-cadherin expression pattern in primary colorectal carcinomas and their metastases reflects disease outcome. World J Gastroenterol 2006; 12: 4304-4309.

29. He X, Chen Z, Jia M, et al. Downregulated E-cadherin expression indicates worse prognosis in Asian patients with colorectal cancer: evidence from meta-analysis. PLoS One 2013; 8: e70858.

30. Jass JR. HNPCC and sporadic MSI-H colorectal cancer: a review of the morphological similarities and differences. Fam Cancer 2004; 3: 93-100.

31. Kaur G, Masoud A, Raihan N, et al. Mismatch repair genes expression defects \& association with clinicopathological characteristics in colorectal carcinoma. Indian J Med Res 2011; 134: 186-192.

32. Kim JH, Rhee YY, Bae JM, et al. Loss of CDX2/CK20 expression is associated with poorly differentiated carcinoma, the CPG island methylator phenotype, and adverse prognosis in microsatellite-unstable colorectal cancer. Am J Surg Pathol 2013; 37: 1532-1541

33. Minoo P, Zlobec I, Peterson M, et al. Characterization of rectal, proximal and distal colon cancers based on clinicopathological, molecular and protein profiles. Int J Oncol 2010; 37: 707-718.

34. Okon K, Zazula M, Rudzki Z, et al. CDX-2 expression is reduced in colorectal carcinomas with solid growth pattern and proximal location, but is largely independent of MSI status. Pol J Pathol 2004; 55: 9-14.

35. Zlobec I, Bihl M, Foerster A, et al. Comprehensive analysis of $\mathrm{CPG}$ island methylator phenotype (CIMP)-high, -low, and -negative colorectal cancers based on protein marker expression and molecular features. J Pathol 2011; 225: 336-343.

36. Funakoshi S, Kong J, Crissey MA, et al. Intestine-specific transcription factor $\mathrm{Cdx} 2$ induces E-cadherin function by enhancing the trafficking of E-cadherin to the cell membrane. Am J Physiol Gastrointest Liver Physiol 2010; 299: G1054-1067.

37. Lugli A, Zlobec I, Minoo P, et al. Prognostic significance of the wnt signalling pathway molecules APC, beta-catenin and E-cadherin in colorectal cancer: a tissue microarray-based analysis. Histopathology 2007; 50: 453-464.

38. Yalcinkaya U, Ozturk E, Ozgur T, et al. P53 expression in synchronous colorectal cancer. Saudi Med J 2008; 29: 826-831.

39. Demirbas S, Sucullu I, Yildirim S, et al. Influence of the c-erb $\mathrm{B}-2, \mathrm{~nm} 23, \mathrm{bcl}-2$ and $\mathrm{p} 53$ protein markers on colorectal cancer. Turk J Gastroenterol 2006; 17: 13-19.

40. Carneiro FP, Ramalho LN, Britto-Garcia S, et al. Immunohistochemical expression of p16, p53, and p63 in colorectal adenomas and adenocarcinomas. Dis Colon Rectum 2006; 49: 588-594.

41. Zhao DP, Ding XW, Peng JP, et al. Prognostic significance of bcl-2 and p53 expression in colorectal carcinoma. J Zhejiang Univ Sci B 2005; 6: 1163-1169.

42. Olsen J, Espersen ML, Jess P, et al. The clinical perspectives of CDX2 expression in colorectal cancer: a qualitative systematic review. Surg Oncol 2014; 23: 167-176.

43. Valentini AM, Renna L, Armentano R, et al. Mismatch repair, p53 and beta-catenin proteins in colorectal cancer. Anticancer Res 2002; 22: 2083-2088.

\title{
Address for correspondence
}

\author{
Ilyas Sayar \\ Departmant of Pathology \\ Faculty of Medicine \\ Erzincan University \\ Erzincan Turkey \\ e-mail: drilyassayar@hotmail.com
}

